\title{
ON THE SUMMATION OF FRACTIONAL POWERS OF MATRICES OVER FINITE FIELDS
}

\author{
Juliano B. Lima and Ricardo M. CAmpello de Souza
}

\begin{abstract}
In this paper, we investigate the summation of fractional powers of matrices over finite fields. More specifically, we show how a fractional power of a matrix of a linear transform over a finite field can be obtained from the linear combination of some specific powers of the same matrix. We use the developed theory to construct matrices related to fractional Fourier and cosine transforms over finite fields.
\end{abstract}

Mathematics subject classification (2010): 12E20, 15B33, 15A18, 43A32.

Keywords and phrases: Finite field transforms, fractional powers of matrices, periodic matrices.

\section{REFERENCES}

[1] D. S. Dummit And R. M. Foote, Abstract Algebra, Wiley, 2003.

[2] J. E. Humphreys, Linear Algebraic Groups, Graduate Texts in Mathematics, Springer, 1998.

[3] L. Lebtahi, O. Romero and N. Thome, Characterizations of $\{K, s+1\}$-potent matrices and applications, Linear Algebra and its Applications 2, vol. 436, 293-306, 2012.

[4] Y. WU AND D. F. LINDER, On the Eigenstructures of Functional K-Potent Matrices and Their Integral Forms, WSEAS Transactions on Mathematics 1, vol. 9, 244-253, 2010.

[5] F. ZHANG, Y. HU, R. TAO AND Y. WANG, New fractional matrix with its applications in image encryption, Optics \& Lasers Technology, vol. 64, 82-93, 2014.

[6] M.-H. YeH AND S.-C. PEI, A method for the discrete fractional Fourier transform computation, IEEE Transactions on Signal Processing 3, vol. 51, 889-891, 2003.

[7] J. B. Lima And R. M. CAmpello DE Souza, The fractional Fourier transform over finite fields, Signal Processing 2, vol. 92, 465-476, 2012.

[8] X. SHA, X. QIU AND L. MEI, Hybrid carrier CDMA communication system based on weighted-type fractional Fourier transform, IEEE Communications Letters 4, vol. 16, 432-435, 2012.

[9] R. TAO, F. ZHANG AND Y. WANG, Linear summation of fractional-order matrices, IEEE Transactions on Signal Processing 7, vol. 58, 3912-3916, 2010.

[10] E. Sejdić, I. DuURović AND L. STANKović, Fractional Fourier transform as a signal processing tool: An overview of recent developments, Signal Processing 6, vol. 91, 1351-1369, 2011.

[11] J. B. Lima AND R. M. CAMPEllo DE SouzA, Fractional cosine and sine transforms over finite fields, Linear Algebra and its Applications, 8, vol. 438, 3217-3230, 2013.

[12] J. B. Lima, R. M. Campello De Souza and D. Panario, The Eigenstructure of finite field trigonometric transforms, Linear Algebra and its Applications, 8, vol. 435, 1956-1971, 2011.

[13] J. B. Lima And R. M. CAmpello De SouZa, Finite field trigonometric transforms, Applicable Algebra in Engineering, Communication and Computing, 5-6, vol. 22, 393-411, 2011.

[14] J. B. Lima, E. A. O. Lima AND F. MAdeIRO, Image encryption based on the finite field cosine transform, Signal Processing: Image Communication 10, vol. 28, 1537-1547, 2013.

[15] J. B. LIMA AND L. F. G. NOVAES, Image encryption based on the fractional Fourier transform over finite fields, Signal Processing, vol. 94, 521-530, 2014.

[16] C. Candan, M. Alper Kutay and H. M. Ozaktas, The discrete fractional Fourier transform, IEEE Trans. Signal Process. 5, vol. 48, 1329-1337, 2000.

[17] D. T. BirTwistle, The Eigenstructure of the Number Theoretic Transforms, Signal Processing 4, vol. 4, 287-294, 1982. 
[18] R. M. Campello de Souza, H. M. de Oliveira, A. N. Kauffman and A. J. A. Paschoal, Trigonometry in Finite Fields and a New Hartley Transform, Proc. IEEE Int. Symp. Information Theory (ISIT'98), 293, 1998.

[19] Cariolaro, G. and Erseghe, T. and Kraniauskas, P., The fractional discrete cosine transform, IEEE Transactions on Signal Processing 4, vol. 50, 902-911, 2002.

[20] R. J. Cintra, V. S. Dimitrov, R. M. Campello de Souza and H. M. De Oliveira, Fragile watermarking using finite field trigonometrical transforms, Signal Processing, Image Communication, vol. 24, 587-597, 2009.

[21] S.-C. PEI, C.-C. WEN AND J. J. Ding, Closed form orthogonal number theoretic transform eigenvectors and the fast fractional NTT, IEEE Trans. on Signal Processing 5, vol. 59, 2124-2135, 2011. 